\title{
Press-extrusion pretreatment of the organic fraction of municipal solid waste for enhanced methane production
}

\author{
Alessandra Cesaro ${ }^{1} \cdot$ Valentina Cieri $^{2} \cdot$ Vincenzo Belgiorno $^{2}$
}

Received: 20 February 2020 / Accepted: 30 August 2020 / Published online: 18 September 2020

(c) The Author(s) 2020

\begin{abstract}
Anaerobic digestion (AD) is a well-established process for the treatment of a wide variety of solid organic substrates, including the organic fraction of municipal solid waste (OFMSW). At industrial scale, the mechanical pretreatment is a fundamental step to reduce OFMSW particle size and to promote the hydrolysis within the subsequent AD process. Among the mechanical pretreatment technologies, press-extrusion has recently raised great interest for its possible application to either enhance the organic load to the digester or improve the overall process stability and methane yields. Aim of this study was in assessing the potential of the press-extrusion pretreatment to improve the performance of OFMSW anaerobic degradation. Batch tests were set up according to a full factorial design of experiments to assess the significance of the main operating parameters. The statistical analysis of results addressed further tests, carried out under semi-continuous feeding mode, to better discuss the possible application of press-extrusion for the greatest valorization of OFMSW under anaerobic conditions.
\end{abstract}

Keywords Biogas $\cdot$ Circular economy $\cdot$ Energy $\cdot$ Pretreatment $\cdot$ Recovery $\cdot$ Solid waste

\section{Introduction}

The organic fraction of municipal solid waste (OFMSW) represents one of the most abundant biomass worldwide. In the European Union, it basically refers to household likebiodegradable waste and its yearly production accounts for approximately $140 \mathrm{Mt}$ [1]. Due to its high moisture content and biodegradability, OFMSW has been traditionally handled via biological processes, including anaerobic digestion (AD).

AD consists of complex biological reactions, occurring in series and carried out by different microbial groups. During the process, the organic substrate is converted into intermediate compounds; these are further degraded to generate a gaseous mixture, mainly composed of methane and carbon dioxide, which can be upgraded and destined to energy

Alessandra Cesaro

alessandra.cesaro@unina.it

1 Department of Civil, Architectural and Environmental Engineering, University of Napoli Federico II, via Claudio 21, 80125 Naples, Italy

2 SEED-Sanitary Environmental Engineering Division, Department of Civil Engineering, University of Salerno, via Giovanni Paolo II, 84084 Fisciano, Salerno, Italy production [2]. The generation of intermediates makes OFMSW an attractive substrate for the production of different chemicals of industrial interest. In this view, several studies are being directed towards the possible generation of lactic acid [3], biofuels [4], polyhydroxyalkanotes [5] and other value added products pursuing the valorization of OFMSW in a biorefinery context.

Industrial $\mathrm{AD}$ processes are largely applied to treat OFMSW, with the main aim of producing methane to be used for energy generation. A residual effluent, namely the digestate, is generated as well and it is applied on soil due to its fertilizer properties. In this regard, AD represents the OFMSW treatment option that better implements the principles of the circular economy, which pursues the extensive recovery of residual streams as well as the minimization of disposal. The identification of suitable strategies to enhance $\mathrm{AD}$ performances is thus fundamental, standing as a focus area of great scientific and technical interest.

It is well known that the mass transfer in each biological step highly influences the production of methane [6]: the hydrolysis of the complex macromolecules into soluble monomers represents, in particular, the rate-limiting phase. Appropriate pretreatments are thus necessary to improve the quality of the substrate fed to the digesters. Different processes have been considered, including chemical [7, 


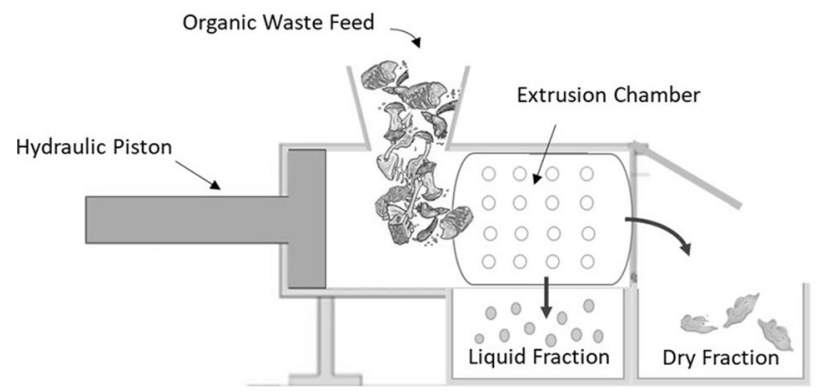

Fig. 1 Schematic representation of a press-extrusion device

8], physical $[9,10]$ and biological $[11,12]$ ones, as well as their combination $[13,14]$. Among these pretreatments, mechanical technologies are those commonly applied at fullscale, with the main aim of reducing OFMSW particles at a size compatible with the microbial attack in the digester. In the last decade, the full-scale mechanical pretreatment of OFMSW has also relied on press-extrusion, which is turning to be very promising. The process is based on the application of a very high pressure to the organic waste, previously fed to an extrusion chamber fitted with holes [15] ranging between 8 and $12 \mathrm{~mm}$. As schematically represented in Fig. 1, the applied pressure squeezes the waste out of the chamber through the holes, forming a liquid fraction (LF), with a moisture content of around $80-85 \%$, which can be used for $\mathrm{AD}$. The portion of the input waste retained in the chamber constitutes a dry, solid fraction, where the impurities and fibre-based components tend to concentrate. Due to its high carbon content, this solid fraction can be either addressed to solid-state biological treatments or used within thermal processes.

Scientific reports show that the distribution of the input organic fraction between the liquid and the solid phases depends on the type of extruder as well as on the waste characteristics. Nevertheless, the liquid fraction may represent up to $80 \%$ of the incoming organic solid waste.

The press-extrusion promotes the reduction of OFMSW particle size as well as the solubilisation of the organic material, so that an improvement of the biodegradability is pursued as well $[6,16]$. Depending on the intensity of the mechanical stress induced by extrusion, the thermal degradation of sugars and amino acids can also occur [16]. However, recent studies have shown that pressure values above $40 \mathrm{MPa}$ determine excessive solubilisation. This results, in turn, in the formation of organic acids hindering the digestion process [6]. The press-extrusion pretreatment generates an organic liquid material that is more homogeneous than the rough waste and suitable to be treated via wet AD systems. This is a further advantage when considering that wet $\mathrm{AD}$ techniques rely on the wide expertise acquired from the field of sewage sludge anaerobic biostabilization.
Wet AD systems are more productive when operated at low organic loads [17], but this condition limits the amount of waste that can be fed to the digester. Press-extruded OFMSW, already partly solubilised, could be then applied as substrate in wet anaerobic digesters to enhance the organic load and increase, in turn, the digester treatment capacity. A further option to improve the organic load to the digester raises from the study of Mu et al. [18], who pointed out that mixing the LF from OFMSW press-extrusion with the solid one originated from the same pretreatment may increase $\mathrm{AD}$ stability.

Aim of this study was in assessing the potential of the press-extrusion pretreatment to optimize the performance of OFMSW anaerobic digestion. To this end, the methane production potential of press-extruded organic waste was assessed via both batch and semi-continuous tests, under different operating conditions.

\section{Materials and methods}

\section{Substrate and inoculum}

OFMSW is heterogeneous according to several factors such as region, season, culture, economic income and demographics. This means that OFMSW composition in different countries is extremely unpredictable. For this reason, the composition of the organic waste used as a substrate in this research (Table 1) was determined on the basis of the average compositional analysis of OFMSW in some European countries, including Italy, as given in the study of MTT Agrifood Research Finland [19]. To simplify the sample preparation, the percentage of mixed meals, drinks and snack fractions, was distributed among the other categories according to the proportionality criterion proposed by Ariunbaatar et al. [20].

Representative OFMSW samples did not undergo pressextrusion, but they were prepared to mimic press-extruded products. The LF representing the press-extruded waste was obtained grinding OFMSW samples while blending it with water, to reach the homogeneity and consistency similar to a jam, as described in scientific literature [21]. The material was stored at $4{ }^{\circ} \mathrm{C}$ no longer than 1 week before use.

Table 1 Composition of OFMSW used in this study

\begin{tabular}{ll}
\hline Fraction & \% Wet weight \\
\hline Fruits and vegetables & 79 \\
Pasta and rice & 5 \\
Bread & 6 \\
Meat and fish & 8 \\
Dairy products & 2 \\
\hline
\end{tabular}


For the purposes of $\mathrm{AD}$ tests, digested sludge was used as inoculum. It was sampled at the anaerobic reactor of the municipal wastewater treatment plant located in Salerno (Italy). This digester works under mesophilic conditions and it receives both the primary and secondary sludge produced during the wastewater treatment. After sampling, the digested sludge was incubated at the same temperature of the AD tests $\left(35^{\circ} \mathrm{C}\right)$ for 5-7 days ahead the experimental start-up, to provide a hunger phase to reduce its own biogas production.

\section{The experimental plan}

The research developed through both batch and semi-continuous AD trials.

Batch AD tests were performed to investigate the effects on biogas production of two factors, namely the organic load and the mixing ratio between the liquid and solid fractions from press-extrusion. For each factor, two values were selected from scientific literature [18, 22], to test a "low" $(-)$ and a "high" (+) level in four different combinations, in accordance with a $2^{2}$ factorial design (Table 2 ).

The results obtained from this set of experiments underwent the analysis of variance (ANOVA), which was performed using the software RStudio.version 3.5.1., provided by RStudio Team [23], to determine the statistical significance of selected variables at a threshold $p$ value of 0.05 .

The same results addressed a second set of experiments, to investigate the effects of total solid (TS) content on the digestion of the LF from OFMSW press-extrusion. The initial TS content of the substrate was adjusted at the desired value of either $10 \%$ or $15 \%$ by adding water.

After completing the second series of experiments, the same conditions were tested in semi-continuous mode.

\section{Experimental set up}

\section{Batch reactors}

AD tests were carried out in batch for 21 days. Glass bottles with a volume of $500 \mathrm{~mL}$ were used as reactors. Substrate samples were added together with the inoculum, to fulfil the

Table 2 Test conditions used in the first set of experiments

\begin{tabular}{lll}
\hline Test run & \multicolumn{2}{l}{ Parameters } \\
\cline { 2 - 3 } & $\begin{array}{l}\text { OFMSW/ } \\
\text { LF }\left(\%_{\mathrm{VS}}\right)\end{array}$ & S/I $\left(\%_{\mathrm{VS}}\right)$ \\
\hline 1 & 25 & 0.5 \\
2 & 75 & 0.5 \\
3 & 25 & 2 \\
4 & 75 & 2 \\
\hline
\end{tabular}

designed experimental conditions. Tap water was added as well, to ensure a working volume of $450 \mathrm{~mL}$ in each flask.

After feeding, the headspaces of the reactors were flushed with nitrogen gas for about $5 \mathrm{~min}$ and then the bottles were sealed with rubber septa and connected by a capillary tube to an inverted $1000 \mathrm{~mL}$ glass bottle containing an alkaline solution $(2 \% \mathrm{NaOH})$, as described by Esposito et al. [24], to collect the produced biogas.

Blank trials containing the sole inoculum were set up as well.

All the reactors were placed in a water bath to ensure mesophilic conditions. Mixing was provided by manually shaking each reactor once a day.

The tests were carried out in triplicate and average values were considered for discussion.

\section{Semi-continuous reactors}

The system consisted of a $5 \mathrm{~L}$ glass reactor, with a working volume of $4.5 \mathrm{~L}$. The operating temperature was $35^{\circ} \mathrm{C}$ and it was controlled by a thermal jacket connected to a thermostatic bath. A magnetic stirring system operating in the range of 900-1300 rpm provided mixing in the reactor. Figure 2 provides a schematic of the experimental set up.

The digester was operated at a hydraulic retention time (HRT) of 30 days, in accordance with the findings of Novarino and Zanetti [21]. It was fed daily to gradually increase TS content in the anaerobic medium up to $12.5 \%$.

Before the test begun, a start-up phase was performed to avoid early failure of the system as well as to promote the acclimation of the microbial population to the target substrate. To this end, the reactor was initially loaded with a mixture of inoculum (87.5\%) and LF (12.5\%) as suggested by $\mathrm{Mu}$ et al. [18]. LF was added gradually, to prevent the system overload unless the inoculum was completely replaced; moreover, after LF addition, the system was not fed until the production of methane became constant.

After the daily feeding, the reactor headspace was flushed with nitrogen and the reactor was closed with a rubber septum.

\section{Analytical setup}

TS, volatile solid (VS), and $\mathrm{pH}$ were analysed in accordance with Standard Methods [25].

Daily methane production was monitored through a water displacement method as described by Esposito et al. [24] and the generated methane volume was normalized to standard temperature and pressure (STP).

The specific methane volume was evaluated as the total volume of methane produced during the digestion period per mass of added substrate, expressed in terms of VS (i.e. $\left.\mathrm{L}_{\mathrm{CH} 4} / \mathrm{kg}_{\mathrm{VS}}\right)$. The methane production of the sole inoculum 
Fig. 2 Scheme of the experimental set up to run the semicontinuous tests

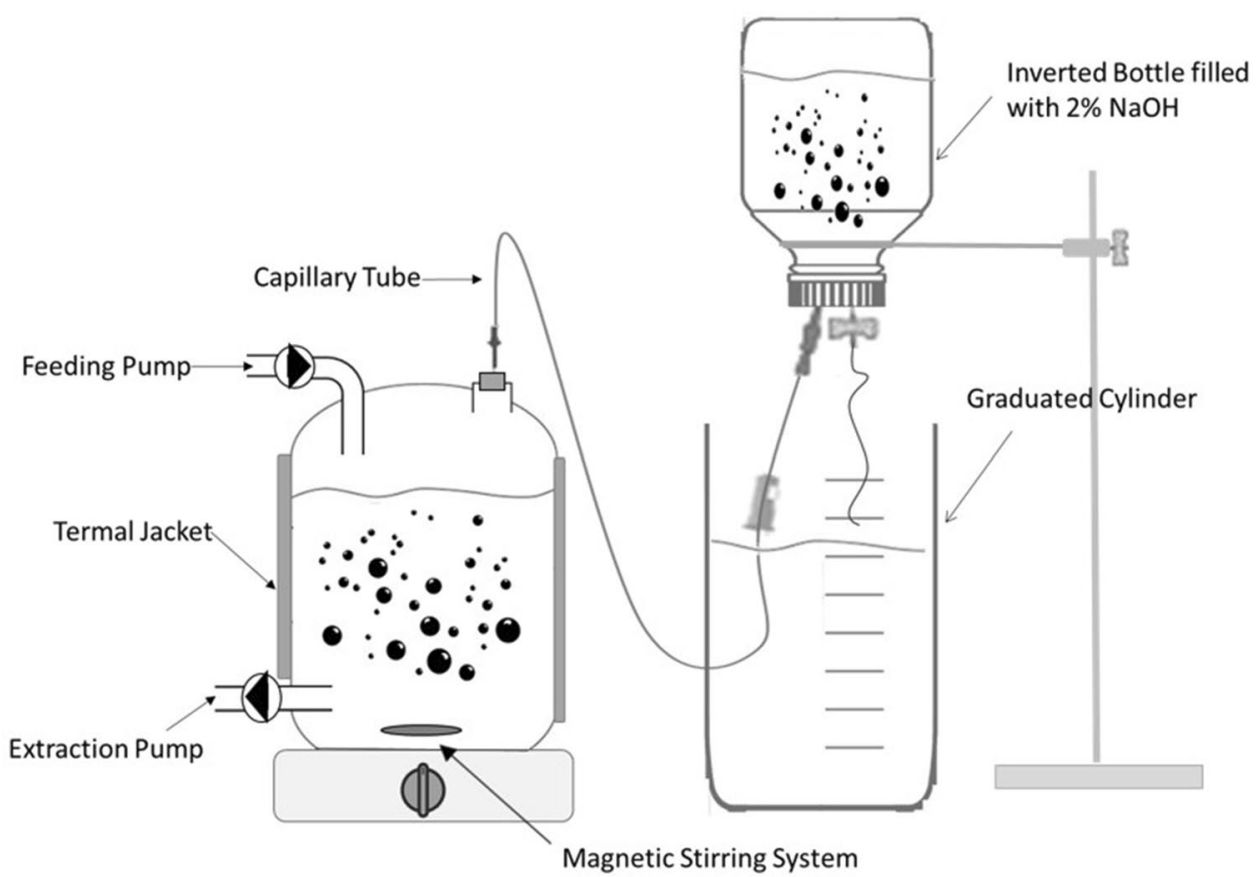

Table 3 Characteristics of OFMSW, liquid fraction (LF) and inoculum (I) used in each set of experiments

\begin{tabular}{|c|c|c|c|}
\hline & $\mathrm{TS}(\% \mathrm{tq})$ & VS (\%TS) & $\mathrm{pH}$ \\
\hline \multicolumn{4}{|c|}{ First set of batch experiments } \\
\hline OFSMW & $41.40 \pm 1.52$ & $96.86 \pm 0.32$ & $4.52 \pm 0.21$ \\
\hline $\mathrm{LF}$ & $28.53 \pm 0.42$ & $95.30 \pm 0.32$ & $4.34 \pm 0.04$ \\
\hline I & $3.36 \pm 0.85$ & $55.54 \pm 4.49$ & $7.43 \pm 0.03$ \\
\hline \multicolumn{4}{|c|}{ Semi-continuous } \\
\hline OFSMW & $22.15 \pm 0.67$ & $93.94 \pm 0.42$ & $4.81 \pm 0.21$ \\
\hline LF & $14.43 \pm 0.06$ & $93.38 \pm 0.22$ & $4.39 \pm 0.14$ \\
\hline I & $2.80 \pm 0.40$ & $65.47 \pm 0.45$ & $7.34 \pm 0.23$ \\
\hline
\end{tabular}

was subtracted from these results to obtain the net methane production from the biomass fed to the reactors under different operating conditions.

\section{Results and discussion}

\section{The chemical-physical characterization of the substrates}

The initial characteristics of OFMSW, LF and inoculum used in the different experimental runs are displayed in Table 3.

Organic waste typically has high moisture as well as VS content: the latter, which is converted into the soluble matter more easily used by microorganisms [26], accounts for the good biodegradability of this kind of waste.
In this study, the VS content was $95.4 \%$ and $94 \%$ for OFMSW and LF, respectively. These values indicate a high potential for biodegradation during AD processes [27] and are comparable with those reported in scientific literature. Nevertheless, if organic waste from full-scale plants is considered, the reported VS values tend to be lower than $90 \%$ on TS basis. This could be due to either a greater quantity of impurities contained in the waste entering an industrial plant or to the variation in the moisture content during the sampling [28].

Depending on the waste characteristics, TS can be variable as well. Bong et al. [29] pointed out that the substrate solubilisation and the subsequent biodegradation is also influenced by high TS content.

The initial TS concentration of the organic waste used in this study ranged between $22.15 \%$ and $41.40 \%$ on wet weight. This suggests that sample preparation was affected by seasonal variation. In this view, Fisgativa et al. [30], analysing 65 food waste samples, reported a variation of the characteristics of organic waste collected in summer and winter.

Compared to rough organic waste, the LF resembling press-extruded waste had obviously a lower TS content [6]. As reported in various literature studies, press-extrusion determines both the increase of the specific surface area and the solubilisation of the substrate. This, in turn, improves the access of microbes and enzymes to the organic substance, promoting the degradation of the slowly degradable compounds [16].

The initial $\mathrm{pH}$ of both OFMSW and LF was acid, ranging between 4 and 5 . These values do not fall in the optimal 
$\mathrm{pH}$ range required for AD. Nevertheless, the inoculum $\mathrm{pH}$ was higher and around 7 . When mixing the inoculum with the substrate, the former provided the microbial consortium to speed up the anaerobic process lag phase as well as the adequate buffer capacity against the acidic conditions of the substrate, so that it was possible to avoid the $\mathrm{pH}$ adjustment before the anaerobic test start.

\section{Effects of OFMSW/LF ratio under different organic load conditions}

The effects of both the OFMSW/LF mixing ratio and the organic load expressed as the substrate-to-inoculum (S/I) ratio were assessed through the analysis of variance (ANOVA). It allows the comparison of the mean values among groups of data, to verify the existence of statistically significant differences. ANOVA was applied to the results of the tests designed according to a factorial experiment, to identify the significance of the chosen factors as well as the possible interaction among the same factors.

Figure 3 plots the cumulative methane production obtained during the batch tests under different operating conditions.

The $\mathrm{pH}$ increase obtained at the end of the tests suggested the proper development of $\mathrm{AD}$. The final $\mathrm{pH}$ values ranged between 7.18 and 7.45. As already mentioned, the inoculum used in this study had a high $\mathrm{pH}$ that indicates a high buffer capacity [27]. It was sufficient to maintain the $\mathrm{pH}$ in a suitable range and to control the possible acidification from the volatile fatty acids (VFA) produced during the initial biodegradation steps.

All the tests showed an increasing methane production trend over time, with final specific production values of $402.1 \pm 95.8 \mathrm{~L} / \mathrm{kg}_{\mathrm{vS}}$ for Test $1\left(\mathrm{OFMSW} / \mathrm{LF}=25 \%{ }_{\mathrm{vS}}\right.$; $\left.\mathrm{S} / \mathrm{I}=0.5 \%{ }_{\mathrm{VS}}\right), 341.8 \pm 71.4 \mathrm{~L} / \mathrm{kg}_{\mathrm{VS}}$ for Test 2 (OFMSW/

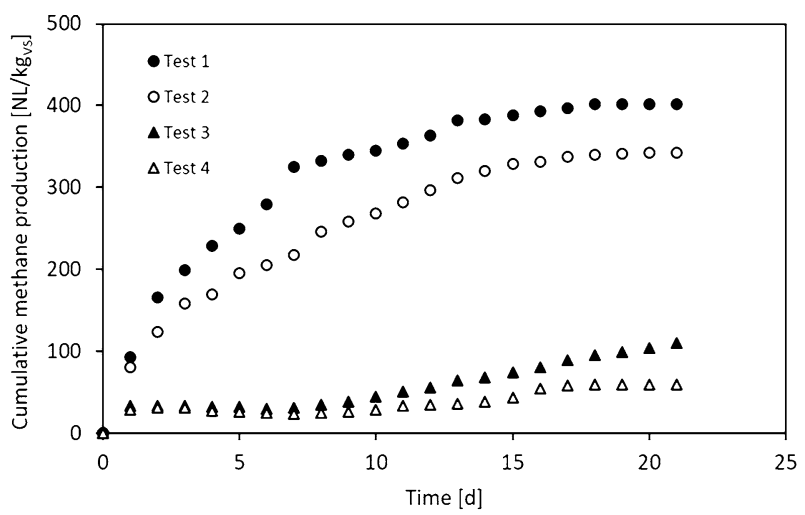

Fig. 3 Methane production under different test conditions (Test 1: $\mathrm{OFMSW} / \mathrm{LF}=25 \%-\mathrm{S} / \mathrm{I}=0.5$; Test $2: \mathrm{OFMSW} / \mathrm{LF}=75 \%-\mathrm{S} / \mathrm{I}=0.5$; Test 3: OFMSW/LF $=25 \%-\mathrm{S} / \mathrm{I}=2$; Test $4: \mathrm{OFMSW} / \mathrm{LF}=75 \%-$ $\mathrm{S} / \mathrm{I}=2$ )
$\left.\mathrm{LF}=75 \%_{\mathrm{vS}} ; \mathrm{S} / \mathrm{I}=0.5 \%_{\mathrm{vS}}\right), 110.4 \pm 78.5 \mathrm{~L} / \mathrm{kg}_{\mathrm{vS}}$ for Test 3 $\left(\mathrm{OFMSW} / \mathrm{LF}=25 \%_{\mathrm{vS}} ; \mathrm{S} / \mathrm{I}=2 \%{ }_{\mathrm{vS}}\right)$ and $59.3 \pm 15.9 \mathrm{~L} / \mathrm{kg}_{\mathrm{VS}}$ for Test $4\left(\mathrm{OFMSW} / \mathrm{LF}=75 \%_{\mathrm{vS}} ; \mathrm{S} / \mathrm{I}=2 \% \mathrm{vS}_{\mathrm{vS}}\right)$.

The lower methane volume as well as the highest variability in the results were observed for both Test 3 and Test 4 , which were operated at the higher $\mathrm{S} / \mathrm{I}$ value. The poor production of methane indicated, in particular, the inhibition of the $\mathrm{AD}$ process, despite the final $\mathrm{pH}$ values.

The statistical analysis pointed out that the $\mathrm{S} / \mathrm{I}$ ratio was the factor having a significant effect $(p<0.05)$ on methane production and that it has no interaction with the OFMSW/ LF ratio. In fact, at the same S/I ratio, mean values between groups are comparable, as it can be observed comparing the results of Test 1 and Test 2 as well as those of Test 3 and Test 4.

When considering the variability within groups, the same factor (S/I ratio) was the one providing the best results at the lowest value. The greater amount of inoculum promoted the proper development of the biological degradation reactions, thus resulting in higher methane generation [22]. Moreover, experimental results seem to indicate that the methane production is positively affected by low OFMSW/LF ratios. This evidence may be attributed to the increase in readily biodegradable material ensured when the amount of OFMSW fed to the digester is lower than that of LF. However, since the interaction is not statistically significant, only the S/I ratio effectively affects the production of methane, regardless of the OFMSW/LF ratio.

It is worth pointing out that the analysis of variance is based on the hypotheses of normal distribution of the residuals and homoscedasticity of the data. The verification of such hypotheses showed that the latter (homoscedasticity of the data) was not complied, meaning that the variances of experimental results are not homogeneous.

Data heteroscedasticity indicates that other factors, which were not considered in the study, influenced the digestion process. In this view, the size of the material [31-33], the composition of the substrate [33], the microbial groups present in the inoculum [34, 35], which may have been slightly different in the single batches, could be recognized as the additional factors affecting the production of methane significantly.

\section{Effects of the TS content}

\section{Batch experiments}

As the statistical analysis showed the significance of the organic load but not that of the OFMSW/LF ratio on methane generation, further batch tests were carried out using LF as substrate at different TS contents, namely $10 \%$ and $15 \%$.

The initial $\mathrm{pH}$ value under both operating conditions was $7.3 \pm 0.01$. At the end of the digestion process, the 


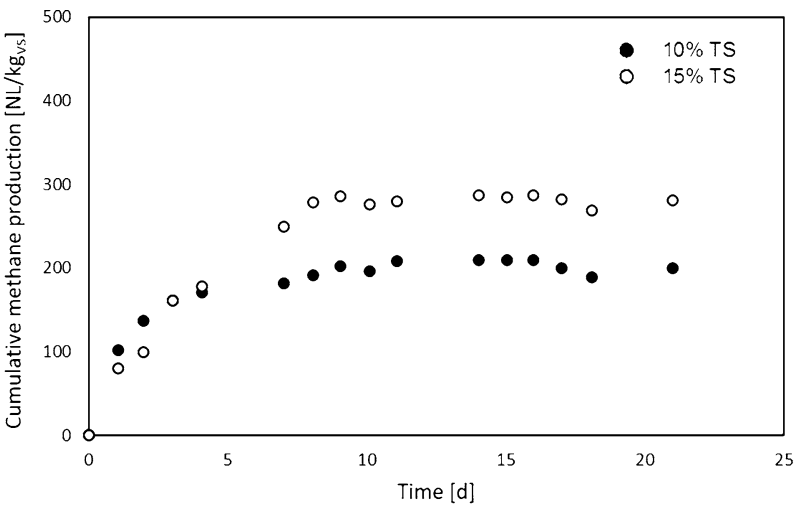

Fig. 4 Methane production from the batch reactors operated at different TS content

average $\mathrm{pH}$ values were $7.51 \pm 0.01$ and $7.49 \pm 0.02$ for the batch with $10 \%$ TS and $15 \%$ TS, respectively. As already observed for the previous batch tests, the buffer capacity of the inoculum was sufficient to keep the $\mathrm{pH}$ within an optimal range for the digestion process, so that any adjustment was necessary.

Figure 4 shows cumulative methane generation during these batch $\mathrm{AD}$ tests.

The trend in methane production was similar for the different tests: in particular, the digestion process developed in the same way during the first 4 days. As reported by Abbassi-Guendouz et al. [36], this evidence indicates the same microbial activity under the different conditions analyzed. From the fourth day, methane production increased for the batch having a higher TS content (15\%), reaching the higher value on the 8 day. Then methane generation started to decrease and a basically steady state was observed untile the end of the test period. When the TS content was $10 \%$, the production of methane increased at a lower rate, reaching a maximum specific volume $40 \%$ lower than the one obtained from batch with $15 \%$ TS.

Experimental results seem to indicate that the less concentrated substrate provided a lower methane production: of course, this evidence could be related to a change in the microbial activity in the different batches. However, this kind of condition is likely to occur either when severe changes in the medium environmental conditions take place [37] or when the substrate composition can lead to the preferable development of a specific microbial consortium [38, 39]. In this study, any variation in methane production potential is likely to be related to the different amount of substrates to be degraded. Nevertheless, it is worth pointing out that this difference is not very relevant when changing the feeding conditions of the digester. In continuous feeding mode, an increase in the substrate concentration can cause the imbalance between hydrolysis/acidogenesis and methanogenesis steps.

\section{Semi-continuous experiments}

Semi-continuous tests were conducted by feeding the reactor only with LF and the organic load was varied by increasing the TS content from an initial value of $10 \%$ up to a maximum of $12.5 \%$. Preliminary semi-continuous tests (data not shown) had indeed pointed out that the system failure occurred for an organic load as high as $15 \%$, so that the range of analysis was restricted to the selected values.

Experimental data showed that an increase in the organic load led to a sensitive reduction in methane production (Fig. 5). This decreased from $246.54 \mathrm{~L} / \mathrm{kg}_{\mathrm{vs}}$ to $81.09 \mathrm{~L} /$ $\mathrm{kg}_{\mathrm{vS}}$ by increasing TS contents from $10 \%$ to $12.5 \%$. This trend appears in agreement with various literature studies, highlighting that an increase in organic loading rate (OLR) resulted in reduced methane yields. As reported by Mao et al. [40], the daily feeding of the digester with large amounts of substrate can bring about changes in the digestion environment and inhibit microbial activity. This is because the rate of hydrolysis/acidogenesis is unbalanced respect to that of methanogenesis, and this causes an accumulation of VFA that cannot be converted into methane. To evaluate the anaerobic digester performance, the digestate that was extracted from the reactor was characterized in terms of pH, TS and VS (Fig. 6).

One of the most common parameter to monitor the anaerobic digestion development at laboratory scale is the $\mathrm{pH}$. In our experiment, the adjustment with $\mathrm{NaOH}$ was necessary when $\mathrm{pH}$ dropped to 5.05-5.69. As previously reported $[38,41]$, the decrease in $\mathrm{pH}$ is caused by the limited buffer capacity of the digestion medium. It probably related to the accumulation of acids, leading to a reduced production of methane. This outcome is further confirmed by the observed trend of both TS and VS in the digestate (Fig. 6). The decrease in both $\mathrm{pH}$ and methane production came along with an increase in TS in the digestate. The content of TS influences the viscosity, fluid dynamic and clogging

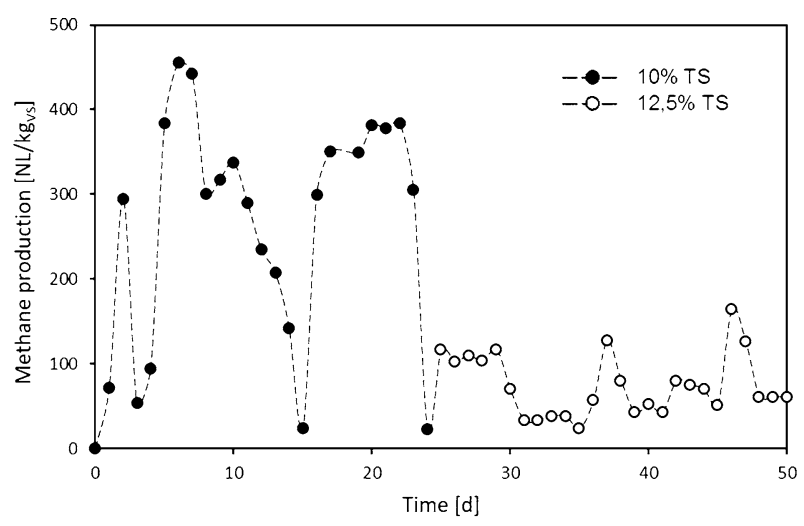

Fig. 5 Methane yields during the semi-continuous anaerobic digestion test 


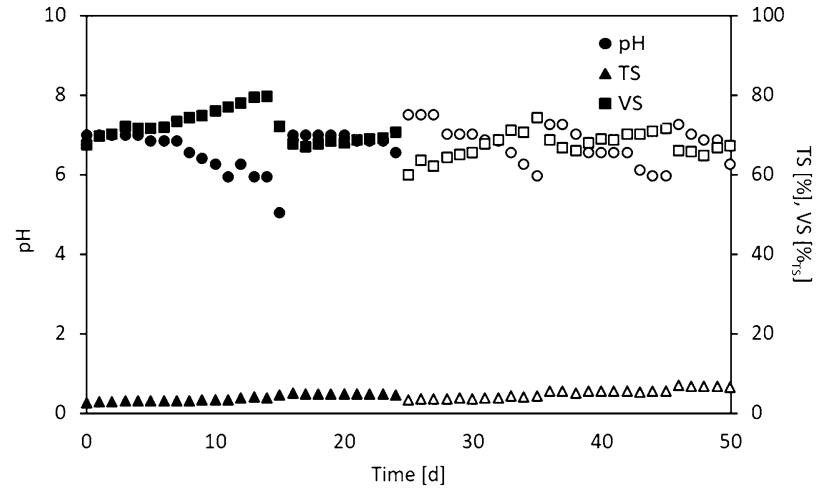

Fig. 6 Semi-continuous anaerobic digester performances in terms of $\mathrm{pH}$, TS and VS

of the digester [42]. Therefore, the greater concentration of TS in the reactor is likely to result in the reduced transfer efficiency of the substrate [18, 43].

In good agreement with what observed by Mu et al. [18], the increase in TS level also led to the formation of foam as well as to problems with the agitation system. This, in turn, limited the release of the biogas, which was trapped in the digestion medium. The inadequate conditions within the digester also influenced the removal efficiency of VS, which decreased as the $\mathrm{pH}$ dropped around 5 (Fig. 6). The subsequent $\mathrm{pH}$ adjustment was provided together with the restoration of the proper mixing conditions in the digester. This determined the sudden increase in methane detection, which is related to the release of the trapped biogas rather than to the immediate recovery of the system. As reported by He et al. [38], the optimal $\mathrm{pH}$ for the methanogenic bacteria ranges between 7.62 and 7.88 . These values were observed only for few days, suggesting that the environmental conditions did not promote the correct development of methanogenic bacteria, capable of correctly degrading the organic substance.

\section{Technical considerations for the scale up}

OFMSW pretreatment is fundamental to ensure the most adequate preparation of the substrate for anaerobic processes. Its use at industrial scale usually relies on mechanical selection processes, mainly aiming at the removal of foreign fractions [44].

Conventional treatments, like sieving, proved to fail in offering an efficient separation of the organic components, as relevant portions of the material that could be addressed to the bioconversion process remain adhered to residues, ending up in the flow usually destined to disposal. Cesaro et al. [45] highlighted that the oversieve retained during the initial screening of OFMSW destined to an integrated anaerobic/ aerobic industrial plant determined a daily loss of about $30 \%$ of the biodegradable portion of the incoming waste. This generated a biogas drop corresponding, in turn, to a daily loss of energy up to $24 \mathrm{MWh}$.

Although the extent of the mechanical selection step depends on the quality of the incoming OFMSW, Jank et al. [46] reported that the application of press-extrusion results in the production of a LF accounting for $87 \%$ of the incoming waste, of whom $90 \%$ consists of organic material. The removal yields of waste materials, such as hard plastics, metals and glass, were observed to be high as well, setting around $90 \%$, since they were properly concentrated in the solid fraction from press-extrusion. These considerations suggest the possible simplification of the pretreatment line within full-scale AD plants, which would result in lower energy consumption and in minor surface occupation as well.

It is worth pointing out that, differently from traditionally applied mechanical selection processes, press-extrusion homogenizes the substrate converting it into a liquid material. This effect, beyond promoting the microbial attack, results in the reduction of viscosity of the matrix in the digester, thus providing the possible decrease of the energy demand for both pumping and stirring systems. Nevertheless, waste pretreatment itself requires energy. The energy demand of mechanical pretreatments tends to enhance as the waste lignocellulosic fraction increases, so as to vary in the range 5-80 kWh/ton of treated waste [47].

Our study pointed out that the pretreatment effectiveness should be evaluated with reference to the integrated pressextrusion/AD process. Despite the operational advantages originating from a press-extrusion pretreatment, in continuously fed system it can promote both acid accumulation and foam formation. The overall feasibility assessment should, thus, consider that the possible increase of the organic load to the digester fed with press-extruded waste can be pursued unless the system can buffer the faster acidogenesis. In this view, the implementation of adequate stirring systems can play a key role [48].

Nevertheless, such consideration could address the use of press-extrusion pretreatment within either two stage $\mathrm{AD}$ plants or co-digestion facilities.

Both strategies have been largely reported to promote the anaerobic stabilization. Two stage AD systems are even much more interesting when considering that methane production can be pursued together with that of both hydrogen and value added reaction intermediates of great industrial interest $[32,49,50]$. The possible increase in the organic load to the digester by applying press-extrusion seems thus suitable to enhance dark fermentation and AD yields in two stage processes, showing a great potential for application as OFMSW pretreatment strategy to pursue the wider implementation of the circular economy principles at industrial level. 


\section{Conclusion}

Press-extrusion has raised as an interesting technology for the treatment of OFMSW prior to AD. This study explored its potential for the improvement of anaerobic digestion performances. To this end, the statistical significance of both OLR and mixing ratio between the liquid and solid fraction from press-extrusion were investigated.

Experimental results showed that anaerobic processes are more significantly affected by the organic load than by the co-digestion of the liquid and solid fractions from pressextrusion. However, at the optimal S/I ratio, a 30\% improvement in methane generation can be pursued by increasing the amount of LF towards that of organic solid waste (OFMSW/ $\mathrm{LF}=25 \%$ vS).

Although higher amounts of press-extruded OFMSW could improve the mass transfer efficiencies within the digester, such increase can result in the process instability, as observed in this study under semi-continuous feeding mode. This condition may result in the reduction of methane generation in mono-digestion system. Nevertheless, it could be better exploited to promote the fermentation step within two stage anaerobic processes. Future studies should thus address the identification of the optimal operating conditions for the integrated press-extrusion/AD process, to pursue the greatest valorization of OFMSW into both energy carriers and value added chemicals of industrial interest in a biorefinery framework.

Acknowledgements The authors wish to thank Paolo Napodano for his valuable support in the experimental work. Alessandra Cesaro would like to thank the Italian Ministry of Education, University and Research (MIUR) who provided financial support for her position as Assistant Professor in the frame of the research project entitled "Dipartimenti di Eccellenza" per Ingegneria Civile Edile e Ambientale - CUPE65D18000820006.

Funding Open access funding provided by Universit $\tilde{A}$ degli Studi di Napoli Federico II within the CRUI-CARE Agreement.

Open Access This article is licensed under a Creative Commons Attribution 4.0 International License, which permits use, sharing, adaptation, distribution and reproduction in any medium or format, as long as you give appropriate credit to the original author(s) and the source, provide a link to the Creative Commons licence, and indicate if changes were made. The images or other third party material in this article are included in the article's Creative Commons licence, unless indicated otherwise in a credit line to the material. If material is not included in the article's Creative Commons licence and your intended use is not permitted by statutory regulation or exceeds the permitted use, you will need to obtain permission directly from the copyright holder. To view a copy of this licence, visit http://creativecommons.org/licenses/by/4.0/.

\section{References}

1. European Union (2018) A Sustainable bioeconomy for europe: strengthening the connection between economy, society and the environment updated bioeconomy strategy

2. Zhang J, Li W, Lee J, Loh KC, Dai Y, Tong YW (2017) Enhancement of biogas production in anaerobic co-digestion of food waste and waste activated sludge by biological co-pretreatment. Energy 137:479-486

3. López Gómez JP, Latorre-Sánchez M, Unger P, Schneider R, Lozano CC, Venus J (2019) Assessing the organic fraction of municipal solid waste for the production of lactic acid. Biochem Eng J 150:1-8

4. Barampouti EM, Mai S, Malamis D, Moustakas K, Loizidou M (2019) Liquid iofuels from the organic fraction of municipal solid waste: a review. Renew Sustain Energy Rev 110:298-314

5. Izaguirre JK, da Fonseca MMR, Fernandes P, Villarán MC, Castañón S, Cesário MT (2019) Upgrading the organic fraction of municipal solid waste to poly(3-hydroxybutyrate). Bioresour Technol 290:1-8

6. Xu S, Kong X, Liu J, Zhao K, Zhao G, Bahdolla A (2016) Effects of high-pressure extruding pretreatment on MSW upgrading and hydrolysis enhancement. Waste Manage 58:81-89

7. Bazargan A, Bazargan M, McKay G (2015) Optimization of rice husk pretreatment for energy production. Renew Energy 77:512-520

8. Pellera FM, Gidarakos E (2018) Chemical pretreatment of lignocellulosic agroindustrial waste for methane production. Waste Manage 71:689-703

9. Dasgupta A, Kumar CM (2019) Enhancement of biogas production from organic fraction of municipal solid waste using hydrothermal pretreatment. In press on Bioresour Technol Reports

10. Rasapoor M, Adl M, Baroutian S, Iranshahi Z, Pazouki M (2019) Energy performance evaluation of ultrasonic pretreatment of organic solid waste in a pilot-scale digester. Ultrason Sonochem 51:517-525

11. Fdez-Güelfo LA, Álvarez-Gallego C, Sales D, Romero LI (2011) The use of thermo-chemical and biological pretreatments to enhance organic matter hydrolysis and solubilisation from organic fraction of municipal solid waste (OFMSW). Chem Eng J 168:249-254

12. Mlaik N, Khoufi S, Hamza M, Masmoudi MA, Sayadi S (2019) Enzymatic pre-hydrolysis of organic fraction of municipal solid waste to enhance anaerobic digestion. Biomass Bioenergy 127:1-9

13. Ariunbaatar J, Panico A, Esposito G, Pirozzi F, Lens PNL (2014) Pretreatment methods to enhance anaerobic digestion of organic solid waste. Appl Energy 123:43-156

14. Cesaro A, Belgiorno V (2014) Pretreatment methods to improve anaerobic biodegradability of organic municipal solid waste fractions. Chem Eng J 240:24-37

15. Gonella C (2011) Preparation of biological waste and municipal solid waste using the press-extrusion process. Proceedings Sardinia 2011, Thirteenth International Waste Management and Landfill Symposium S. Margherita di Pula, Cagliari, Italy; 3-7 October 2011. CISA Publisher, Italy

16. Hjorth M, Granitz K, Adamsen APS, Moller HB (2011) Extrusion as a pretreatment to increase biogas production. Bioresour Technol 102:4989-4994

17. Logan M, Safi M, Lens P, Visvanathan C (2019) Investigating the performance of internet of things based anaerobic digestion of food waste. Process Saf Environ. 127:277-287

18. Mu L, Zhang L, Zhu K, Ma J, Li A (2018) Semi-continuous anaerobic digestion of extruded OFMSW: process performance and energetic evaluation. Bioresour Technol 247:103-115 
19. MTT Agrifood Research Finland (2010) Compositional analysis of food waste from study sites in geographically distinct regions of Europe

20. Ariunbaatar J, Panico A, Frunzo L, Esposito G, Lens PNL, Pirozzi F (2014) Enhanced anaerobic digestion of food waste by thermal and ozonation pretreatment methods. J Environ Manage 146:142-149

21. Novarino D, Zanetti MC (2012) Anaerobic digestion of extruded OFMSW. Bioresour Technol 104:44-50

22. Haider MR, Zeshan YS, Malik RN, Visvanathan C (2015) Effect of mixing ratio of food waste and rice husk co digestion and substrate to inoculum ratio on biogas production. Bioresour Technol 190:451-457

23. RStudio Team (2020) RStudio: integrated development for R. RStudio, Boston

24. Esposito G, Frunzo L, Liotta F, Panico A, Pirozzi F (2012) Biomethane potential tests to measure the biogas production from the digestion and co-digestion of complex organic substrates. Open Environ Eng J 5:1-8

25. AWWA-APHA-WEF (1998) Standard Methods for the Examination of Water and Wastewater, 20th ed. AWWA, APHA, WEF, Washington, DC

26. Ma Y, Gu J, Liu Y (2018) Evaluation of anaerobic digestion of food waste and waste activated sludge: soluble COD versus its chemical composition. Sci Total Environ 643:21-27

27. Pavi S, Kramer LE, Gomes LP, Miranda LAS (2017) Biogas production from co-digestion of organic fraction of municipal solid waste and fruit and vegetable waste. Bioresour Technol 228:362-367

28. Zhang R, El-Mashad HM, Hartman K, Wang F, Liu G, Choate C, Gamble P (2007) Characterization of food waste as feedstock for anaerobic digestion. Bioresour Technol 98:929-935

29. Bong CP, Lim LY, Lee CT, Klemeš JJ, Ho CS, Ho WS (2018) The characterisation and treatment of food waste for improvement of biogas production during anaerobic digestion-a review. J Clean Prod. 172:1545-1558

30. Fisgativa H, Tremier A, Dabert P (2016) Characterizing the variability of food waste quality: a need for efficient valorisation through anaerobic digestion. Waste Manage 50:264-274

31. Izumi K, Okishio YK, Nagao N, Niwa C, Yamamoto S, Toda $\mathrm{T}$ (2010) Effects of particle size on anaerobic digestion of food waste. Int Biodeterior Biodegradation 64:601-608

32. Mirmohamadsadeghi S, Karimi K, Tabatabaei M, Aghbashlo M (2019) Biogas production from food wastes: a review on recent developments and future perspectives. Bioresour Technol Rep. $7: 1-10$

33. Siddique MNI, Wahid ZA (2018) Achievements and perspectives of anaerobic co-digestion: a review. J Clean Prod. 194:359-371

34. Khalid A, Arshad M, Anjum M, Mahmood T, Dawson L (2011) The anaerobic digestion of solid organic waste. Waste Manage 31:1737-1744

35. Kong X, Xu S, Liu J, Li H, Zhao K, He L (2016) Enhancing anaerobic digestion of high-pressure extruded food waste by inoculum optimization. J Environ Manage 166:31-37

36. Abbassi-Guendouz A, Brockmann D, Trably E, Dumas C, Delgenès JP, Steyer JP, Escudié R (2012) Total solids content drives high solid anaerobic digestion via mass transfer limitation. Bioresour Technol. 111:55-61

37. Pirozzi F, Panico A (2012) Digerire Anaerobicamente la Frazione Organica dei Rifiuti. Ambiente Rischio Comunicazione (Quadrimestrale di analisi e monitoraggio ambientale). 2:47-60

38. He Q, Li L, Xuya PX (2017) Early warning indicators and microbial mechanisms for process failure due to organic overloading in food waste digesters. J Environ Eng 143(12):1-8

39. Peces M, Astals S, Jensen PD, Clarke WP (2018) Deterministic mechanisms define the long-term anaerobic digestion microbiome and its functionality regardless of the initial microbial community. Water Res 141:366-376

40. Mao C, Feng Y, Wang X, Ren G (2015) Review on research achievements of biogas from anaerobic digestion. Renew Sust Energ Rev. 45:540-555

41. Babaee A, Shayegan J (2011) Effect of organic loading rates (OLR) on production of methane from anaerobic digestion of vegetables waste. World Renew. Energy Congress 2011-Sweden 8-3 May, Linkoping

42. Chen X, Yan W, Sheng K, Sanati M (2014) Comparison of highsolids to liquid anaerobic co-digestion of food waste and green waste. Bioresour Technol 154:215-221

43. Gou C, Yang Z, Huang J, Wang H, Xu H, Wang L (2014) Effects of temperature and organic loading rate on the performance and microbial community of anaerobic co-digestion of waste activated sludge and food waste. Chemosphere 105:146-151

44. Bolzanella D, Battistoni P, Susini C, Cecchi F (2002) Anaerobic codigestion of waste activated sludge and OFMSW: the experiences of Viareggio and Treviso plants (Italy). Water Sci Technol 53(8):203-211

45. Cesaro A, Russo L, Belgiorno V (2015) Combined anaerobic/ aerobic treatment of OFMSW: performance evaluation using mass balances. Chem Eng J 267:16-24

46. Jank A, Müller W, Schneider I, Gerke F, Bockreis A (2015) Waste Separation Press (WSP): a mechanical pretreatment option for organic waste from source separation. Waste Manage 39:71-77

47. Paritosh K, Monika YM, Mathur S, Balan V, Liao W, Pareek N, Vivekanand V (2018) Organic fraction of municipal solid waste: overview of treatment methodologies to enhance anaerobic biodegradability. Front Energy Res. 6(75):1-17

48. Lindmark J, Eriksson P, Thorin E (2014) The effects of different mixing intensities during anaerobic digestion of the organic fraction of municipal solid waste. Waste Manage 34(8):1391-1397

49. Ren Y, Yu M, Wu C, Wang Q, Gao M, Huang Q, Liu Y (2018) A comprehensive review on food waste anaerobic digestion: research updates and tendencies. Bioresour Technol 247:1069-1076

50. Tyagi VK, Fdez-Güelfo LA, Zhou Y, Álvarez-Gallego CJ, Romero GLI, Ng WJ (2018) Anaerobic co-digestion of organic fraction of municipal solid waste (OFMSW): progress and challenges. Renew Sustain Energy Rev 93:380-399

Publisher's Note Springer Nature remains neutral with regard to jurisdictional claims in published maps and institutional affiliations. 